\title{
SPECTRAL COMPOSITION OF THE LIGHT OF CHAETOPTERUS
}

\author{
By J. A. C. Nicol \\ The Plymouth Laboratory
}

(Text-figs. I-I3)

The light of Chaetopterus has a bluish hue. From visual examination Lankester (1868) judged that the emission spectrum extended from about 440 to $550 \mathrm{~m} \mu$ (wavelengths estimated by Harvey, 1952). Other polychaetes said to produce bluish luminescence are found in the families Alciopidae, Syllidae and Terebellidae. The light of Tomopteridae and Cirratulidae is described as yellow or yellow-green (Harvey, 1955). The spectral composition of the light of polynoids has now been measured. It is yellow-green in colour, with maximal emission at about $5 \mathrm{I} 5 \mathrm{~m} \mu$ (Nicol, I957).

The spectral composition of the light of Chaetopterus variopedatus is here described. Various physiological aspects of the response, some of them pertinent to the present investigation, have already been dealt with (Nicol, I $952 a-c)$. The light is produced by a luminescent secretion discharged into the surrounding sea water. When the glands on segment xII discharge, the light rises to maximal intensity in about $\mathrm{I}_{4} \mathrm{sec}$, and the whole response lasts some $5 \mathrm{~min}$.

\section{MATERIALS AND METHODS}

Chaetopterus was removed from its tube, and the anterior region (head) was cut off. The head was pinned out in a black dish, and light was evoked by electrical stimulation of the luminescent glands lying at the bases of the aliform notopodia (segment xII) (Nicol, I952 $a, b$ ).

To analyse the spectral composition of the light, a multiplier phototube and a series of coloured filters were used. The photomultiplier was connected to a cathode-ray oscilloscope, and photographic records were made of the deflexion of the oscilloscope trace on moving paper.

The filters used were Ilford spectrum filters nos. 60I-608, covering the visible range (about 400-700 $\mathrm{m} \mu$ ), Chance's purple (OV I), and an ultra-violet filter transmitting from about $300-400 \mathrm{~m} \mu$. A set of filters was mounted in an opaque disc which could be rotated beneath the cathode of a photomultiplier tube. Apertures were cut at regular intervals about the margin of the disc, and a filter was placed over each aperture. The disc was arranged so that the filtercovered apertures passed across the face of the photocathode (arrangement shown in Fig. I). The dish containing the animal was placed under the disc, close to the filters. 
Since the light varies in intensity, it was necessary to have some method of registering changes in light intensity, while records of intensity of filtered light in different spectral regions were obtained. This was accomplished by using a series of identical filters (hereafter called reference filters), one of which was placed between each of the other spectral filters. By this means it was possible to gauge the relative light intensity at the beginning and end of each measurement made with a given spectral filter. For reference filters I employed either Ilford blue-green 603 , or Ilford green 604 . From the intensity of the light passed by the reference filters, it was possible to correct the records obtained with other spectral filters, so that all the data referred to light of the same initial energy-content before filtration.

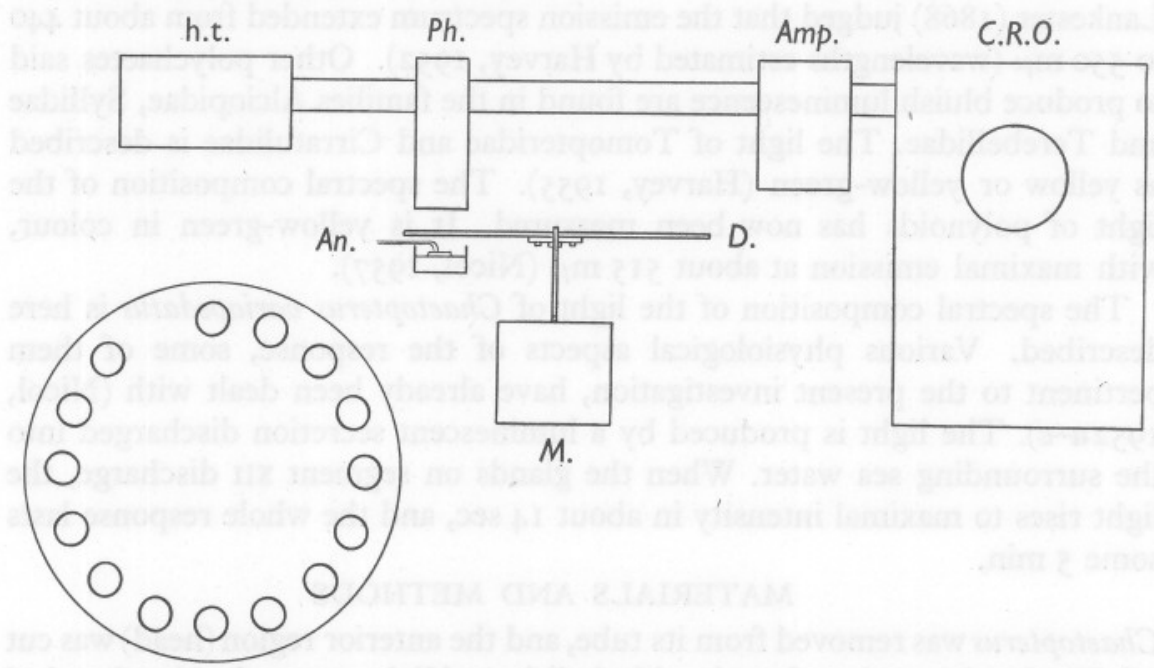

Fig. I. Diagram of apparatus. Amp., amplifier; An., animal; D., disc; C.R.O., cathode-ray oscilloscope; h.t., high tension supply; M., variable speed motor. The disc is shown in surface view at the lower left.

In order to reduce the disparity in magnitude of responses given with the various filters, neutral filters were used in conjunction with Ilford spectrum filters nos. 60I-604. They were either Chance's neutral glass or Ilford neutral density filters. Four combinations of filters that were used are shown in Table $\mathrm{I}$. The filters are given in the order in which they passed across the face of the multiplier phototube. A blank opaque space was left between each pair of contiguous filters to separate the records clearly. At one point on the disc there was a double blank space as a position-marker, to show when the disc had made one complete rotation, and to provide a means of relating the seriated responses to the filters in their order of rotation. Thus, in disc I, when the filters were rotated in order from red to violet, the photographic trace would show: nil deflexion, long duration (=double space); deflexion (=blue-green filter); nil deflexion, short duration (=single space); deflexion (=red filter); 
nil deflexion, short duration (= single space); deflexion (=blue-green filter); etc. Some records, described later, are shown in Figs. 2 and 3.

The transmission of all filters was measured in a spectrophotometer (Unicam, S.P. 500).

The photomultiplier was an E.M.I. no. 6685 , having high sensitivity in the violet and very low sensitivity in the red. The spectral sensitivity of the

\section{TABLE 1. FOUR COMBINATIONS OF FILTERS, LISTED IN ORDER OF ROTATION}

Disc I

Double space

I. Ilford blue-green 603 + Ilford neutral density (D. 0.5)

2. Ilford red 608

3. Ilford blue-green 603 + Ilford neutral density (D. 0.5)

4. Ilford orange 607

5. Ilford blue-green $603+$ Ilford neutral density (D. 0.5)

6. Ilford yellow 606

7. Ilford blue-green $603+$ Ilford neutral density (D. 0.5)

8. Ilford yellow-green 605

9. Ilford blue-green 603 + Ilford neutral density (D. 0.5)

ro. Ilford green 604 + Ilford neutral density (D. 0.5)

II. Ilford blue-green 603 + Ilford neutral density (D. 0.5$)$

I2. Ilford blue 602 + Ilford neutral density (D. 0.5 )

13. Ilford blue-green 603 + Ilford neutral density (D. 0.5)

I4. Ilford violet 601

I5. Ilford blue-green $603+$ Ilford neutral density (D. 0.5)

\section{Disc III}

Double space

I. Ilford green 604

2. Ultra-violet

3. Ilford green 604

4. Ilford yellow 606

5. Ilford green 604

6. Ilford yellow-green 605

7. Ilford green 604

8. Ilford blue-green $603+$ Chance neutral $\mathrm{ON}_{3 \mathrm{I}}$

9. Ilford green 604

Io. Ilford blue $602+$ Chance neutral ON 32

II. Ilford green 604

I2. Ilford violet $601+$ Chance neutrals $\mathrm{ON}_{32}+\mathrm{ON}_{33}$

I3. Ilford green 604

14. Chance OV I

I5. Ilford green 604

\section{Disc II}

Double space

I. Ilford green 604

2. Ilford orange 607

3. Ilford green 604

4. Ilford yellow 606

5. Ilford green 604

6. Ilford yellow-green 605

7. Ilford green 604

8. Ilford blue-green $60_{3}+$ Chance neutral $\mathrm{ON}_{31}$

9. Ilford green 604

10. Ilford blue $602+$ Chance neutral $\mathrm{ON}_{32}$

II. Ilford green 604

I2. Ilford violet $60 \mathrm{I}+$ Chance neutral ON 33

I3. Ilford green 604

\section{Disc IV}

Double space

I. Ilford red 608

2. Ilford green 604

3. Ilford orange 607

4. Ilford green 604

5. Ilford yellow 606

6. Ilford green 604

7. Ilford yellow-green 605

8. Ilford green 604

9. Ilford blue-green $60_{3}+$ Chance neutral $\mathrm{ON}_{3 \mathrm{I}}$

Io. Ilford green 604

II. Ilford blue $602+$ Chance neutral $\mathrm{ON}_{32}$

I2. Ilford green 604

13. Ilford violet $60 \mathrm{I}+$ Chance neutral ON 33

14. Ilford green 604

I5. Chance OV I

I6. Ilford green 604 
photocathode of this tube was determined by the National Physical Laboratory. Voltage for the photomultiplier was supplied by a stabilized power pack. The mains voltage for oscilloscope and power pack was held steady by a voltage stabilizer.

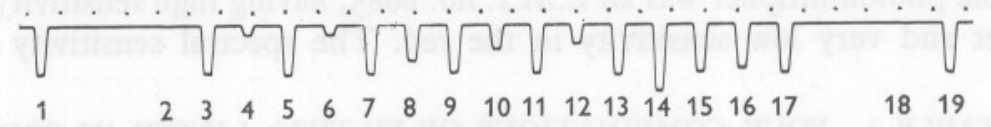

Fig. 2

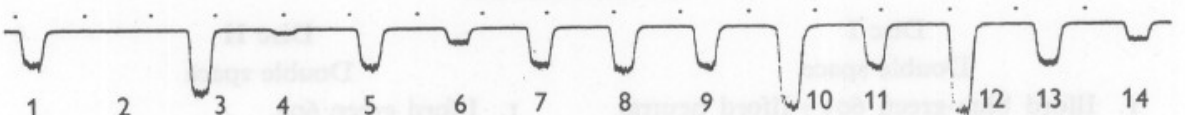

Fig. 3

Fig. 2. Photographic record of oscillograph deflexions given by artificial light source (lamp $2360^{\circ} \mathrm{K}+$ Chance blue-green $\mathrm{OB} 2$ ), interrupted by rotation of disc IV. Responses as follows: I, green 604 ; double space; 2 , red $608 ; 3$, green $604 ; 4$, orange $607 ; 5$, green $604 ; 6$, yellow 606; 7 , green $604 ; 8$, yellow-green $605 ; 9$, green 604 ; 10, blue-green $603 ; 11$, green $604 ; 12$, blue $602 ; 13$, green $604 ; 14$, violet 601 ; 15 , green $604 ; 16$, purple OVI; 17 , green 604 ; double space; 18 , red 608; 19, green 604 .

Fig. 3. Similar record for the light of Chaetopterus, interrupted by disc III. Responses as follows: 1 , green $604 ; 2$, ultra-violet; 3 , green $604 ; 4$, yellow $606 ; 5$, green $604 ; 6$, yellow-green 605 ; 7 , green $604 ; 8$, blue-green $603 ; 9$, green 604 ; Io, blue 602 ; I I, green 604 ; 12 , violet 601 ; I3, green 604; I4, deep purple OV I. Time, both records, $\frac{1}{5} \mathrm{sec}$.

In order to calculate the relative spectral energy of a light source by the method here adopted, it is necessary to know the combined effect of spectral sensitivity of the photomultiplier $\left(S_{\lambda}\right)$ and spectral transmission of each filter $\left(T_{\lambda}\right)$. Let $R_{x}$ be the response for a given filter $x$, and $E_{\lambda}$ the relative spectral energy of emitted light. Then

$$
\begin{aligned}
& R_{x} \propto E_{\lambda} \int S_{\lambda} T_{\lambda} \mathrm{d} \lambda, \\
& \therefore E_{\lambda} \propto \frac{R_{x}}{\int S_{\lambda} T_{\lambda} \mathrm{d} \lambda} .
\end{aligned}
$$

Plots of $S_{\lambda} T_{\lambda}$ against $\lambda$ are given in Figs. 4 and 5. The areas under curves $S_{\lambda} T_{\lambda}$ were used to represent the integrals for each filter

$$
\eta_{x}=\int S_{\lambda} T_{\lambda} \mathrm{d} \lambda .
$$

The mean wavelength $($ mean $\lambda$ ) for each filter was taken from the centre of gravity of the areas under the curves. Values for $\eta_{x}$ and mean $\lambda$ are given in Table 2.

All measurements of Chaetopterus light were made at a room-temperature of $18-19^{\circ} \mathrm{C}$. 


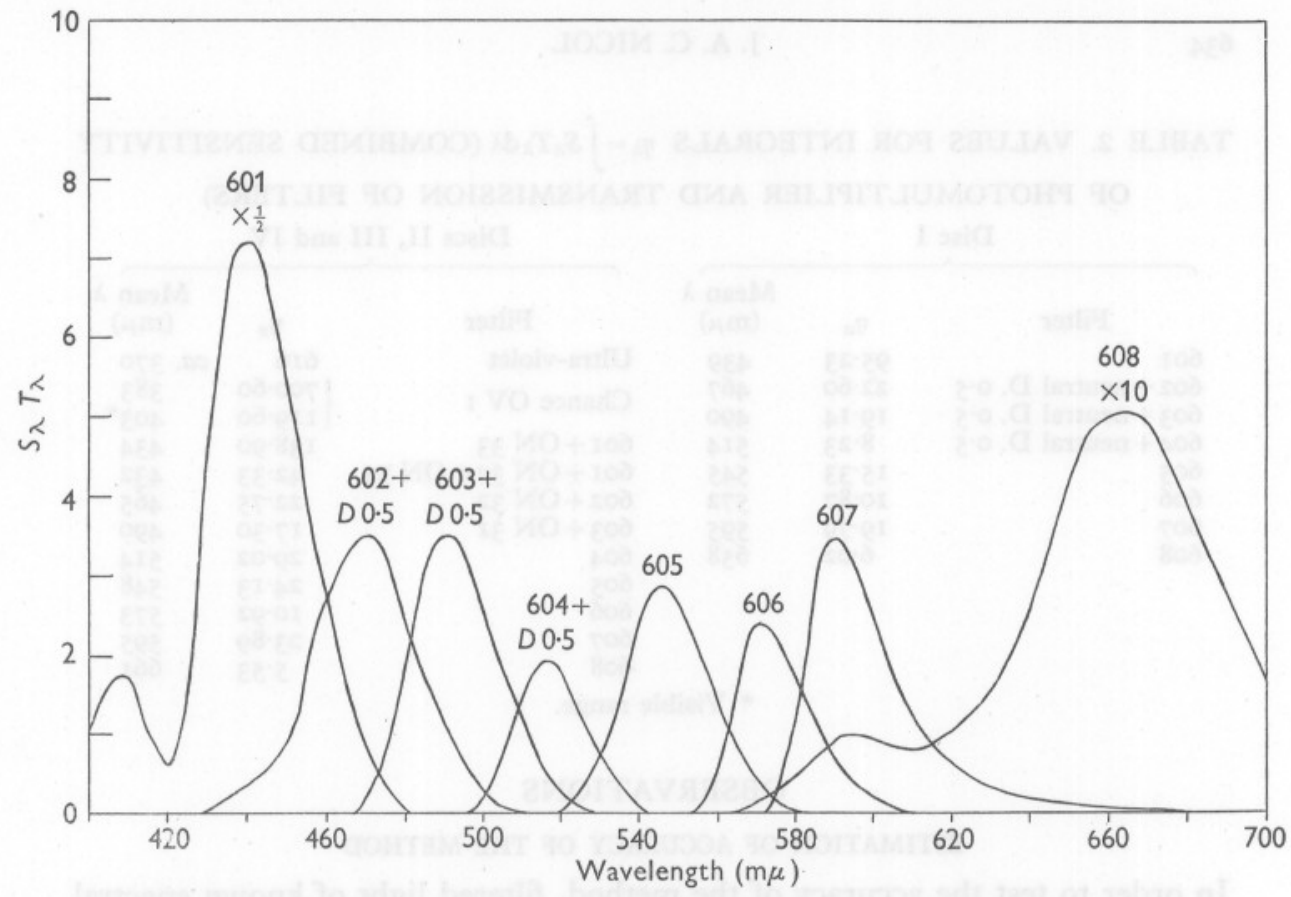

Fig. 4. Plots of $S_{\lambda} T_{\lambda}$ against $\lambda$ for the series of Ilford gelatine filters used in disc I. $S_{\lambda}=$ sensitivity of photomultiplier $6685 ; T_{\lambda}=$ transmission of filters. An Ilford neutral density filter (density D. $=0.5$ ) was used with each of filters 602 to 604 . All filters were mounted between two pieces of Perspex.

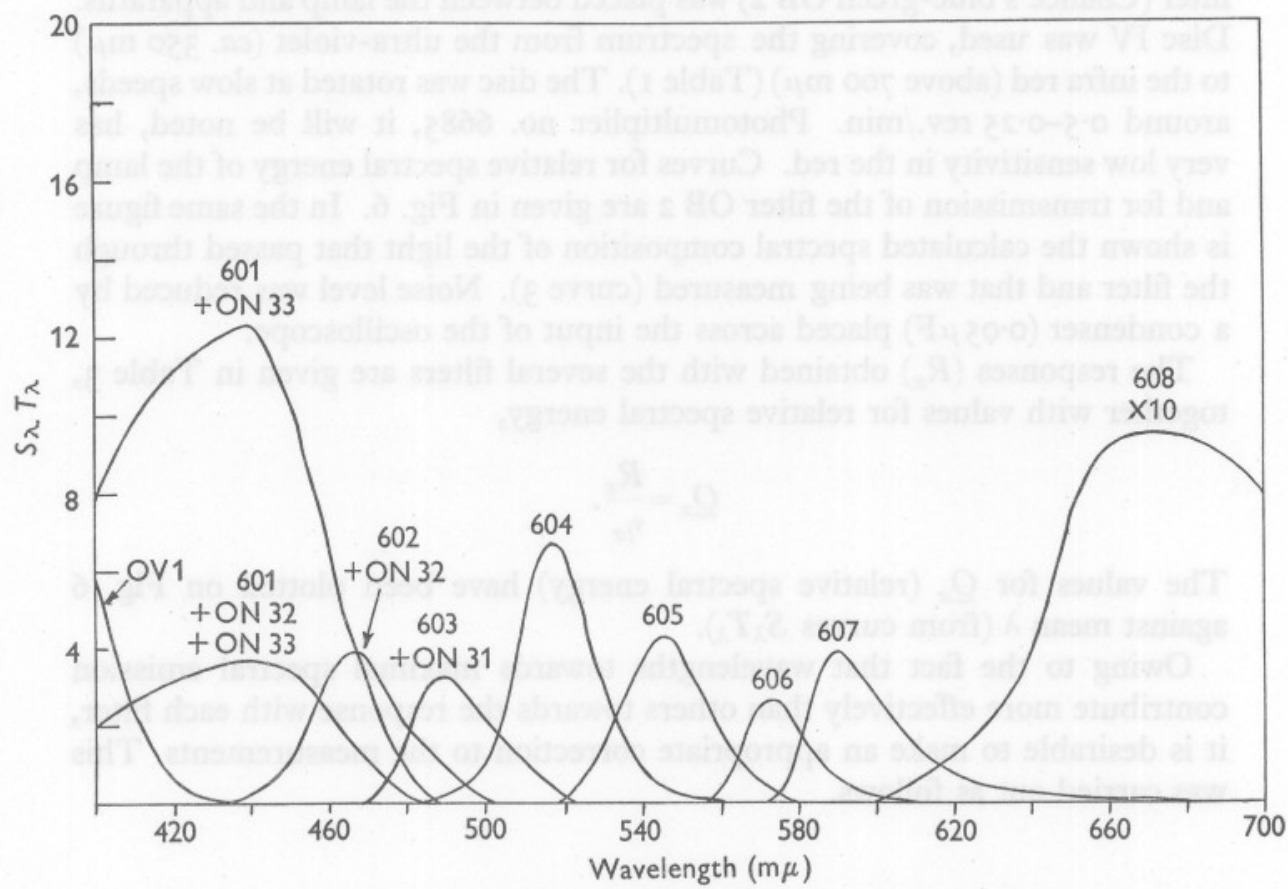

Fig. 5. Plots of $S_{\lambda} T_{\lambda}$ for the various filters used in discs II, III and IV. Filters 60I to 608 were gelatine, mounted in glass; the remainder glass. 
TABLE 2. VALUES FOR INTEGRALS $\eta_{\lambda}=\int S_{\lambda} T_{\lambda} \mathrm{d} \lambda$ (COMBINED SENSITIVITY OF PHOTOMULTIPLIER AND TRANSMISSION OF FILTERS)

Disc I

Filter
601
$602+$ neutral D. $0 \cdot 5$
$603+$ neutral D. $0 \cdot 5$
$604+$ neutral D. $0 \cdot 5$
605
606
607
608

$\begin{array}{cc}\eta_{x} & \begin{array}{c}\text { Mean } \lambda \\ (\mathrm{m} \mu)\end{array} \\ 95 \cdot 23 & 439 \\ 22 \cdot 60 & 467 \\ 19 \cdot 14 & 490 \\ 8.23 & 514 \\ 15.33 & 545 \\ 10.87 & 572 \\ 19 \cdot 79 & 595 \\ 6.02 & 658\end{array}$

* Visible range.
Discs II, III and IV

\begin{tabular}{|c|c|c|}
\hline Filter & $\eta_{\infty}$ & $\underset{(\mathrm{m} \mu)}{\operatorname{Mean} \lambda}$ \\
\hline Ultra-violet & 616 & ca. 370 \\
\hline Chance OV I & $\left\{\begin{array}{l}700 \cdot 60 \\
119 \cdot 60\end{array}\right.$ & $\begin{array}{l}383 \\
403^{\star}\end{array}$ \\
\hline $60 \mathrm{I}+\mathrm{ON} 33$ & 138.90 & 434 \\
\hline $60 \mathrm{I}+\mathrm{ON}_{32}+\mathrm{ON}_{33}$ & $42 \cdot 33$ & 432 \\
\hline $602+\mathrm{ON}_{32}$ & $22 \cdot 75$ & 465 \\
\hline $603+\mathrm{ON}_{3} \mathrm{I}$ & $17 \cdot 30$ & 490 \\
\hline 604 & $29 \cdot 02$ & \\
\hline 605 & $24 \cdot 13$ & 548 \\
\hline 606 & 10.92 & \\
\hline $\begin{array}{l}607 \\
608\end{array}$ & $\begin{array}{r}23.89 \\
5.53\end{array}$ & $\begin{array}{l}595 \\
661\end{array}$ \\
\hline & & \\
\hline
\end{tabular}

\section{OBSERVATIONS}

In order to test the accuracy of the method, filtered light of known spectral composition was measured by means of a disc of filters, photomultiplier and oscilloscope. Constant light was provided from a substandard lamp of colour temperature $2360^{\circ} \mathrm{K}$, obtained from the National Physical Laboratory. A blue filter (Chance's blue-green OB 2) was placed between the lamp and apparatus. Disc IV was used, covering the spectrum from the ultra-violet (ca. $350 \mathrm{~m} \mu$ ) to the infra red (above $700 \mathrm{~m} \mu$ ) (Table I). The disc was rotated at slow speeds, around $0.5-0.25$ rev./min. Photomultiplier no. 6685 , it will be noted, has very low sensitivity in the red. Curves for relative spectral energy of the lamp and for transmission of the filter $\mathrm{OB} 2$ are given in Fig. 6. In the same figure is shown the calculated spectral composition of the light that passed through the filter and that was being measured (curve 3). Noise level was reduced by a condenser $(0.05 \mu \mathrm{F})$ placed across the input of the oscilloscope.

The responses $\left(R_{x}\right)$ obtained with the several filters are given in Table 3 , together with values for relative spectral energy,

$$
Q_{x}=\frac{R_{x}}{\eta_{x}} .
$$

The values for $Q_{x}$ (relative spectral energy) have been plotted on Fig. 6 against mean $\lambda$ (from curves $S_{\lambda} T_{\lambda}$ ).

Owing to the fact that wavelengths towards maximal spectral emission contribute more effectively than others towards the response with each filter, it is desirable to make an appropriate correction to the measurements. This was carried out as follows. 


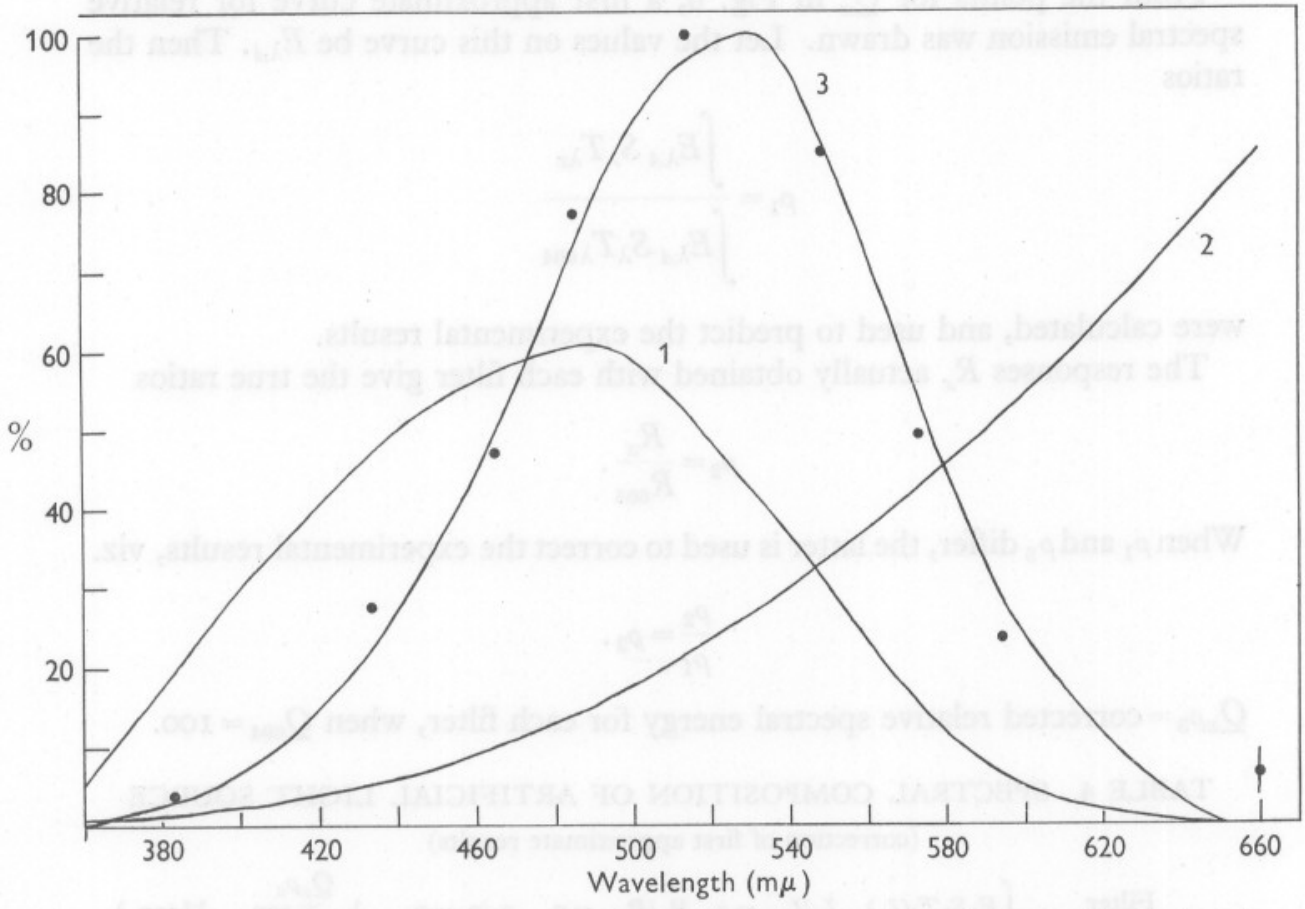

Fig. 6. Curves for (I) transmission (\%) of a blue filter, Chance OB 2; (2) spectral emission of a substandard lamp (colour temperature $2360^{\circ} \mathrm{K}$ ), and (3) calculated spectral composition of light passed by filter $\mathrm{OB}_{2}\left(T_{\lambda} \mathscr{f}_{\lambda}\right)$. Relative $\mathcal{F}_{\lambda}$ based on $\mathcal{f}=\mathrm{I}$ at $\lambda=590 \mathrm{~m} \mu$ (from Skogland, 1929). Relative $T_{\lambda} \mathcal{F}_{\lambda}$ based on $T \mathcal{f}=100$ at $\lambda=530 \mathrm{~m} \mu$. Curve (2), $\times 50$. The points are measured values for spectral composition of light passed by filter $\mathrm{OB}_{2}$.

\section{TABLE 3. MEASUREMENT OF SPECTRAL COMPOSITION OF AN ARTIFICIAL LIGHT SOURCE}

Lamp of colour temperature $2360^{\circ} \mathrm{K}+$ Chance blue-green filter OB 2. Responses and first approximation of relative spectral energy.

\begin{tabular}{|c|c|c|c|}
\hline Filter & $\underset{(\mathrm{m} \mu)}{\operatorname{Mean} \lambda}$ & Response $R_{x}$ & $R_{x} / \eta_{x}=Q_{x}$ \\
\hline OV I & 383 & Io & 0.0143 \\
\hline $601+O N 33$ & 434 & 15 & 0.1080 \\
\hline $602+\mathrm{ON}_{32}$ & 465 & $4 \cdot 2$ & 0.1846 \\
\hline $603+\mathrm{ON}_{3} \mathrm{I}$ & 490 & $5 \cdot 2$ & 0.3006 \\
\hline 604 & 514 & II 3 & 0.3894 \\
\hline 605 & 548 & $8 \cdot 0$ & 0.3315 \\
\hline 606 & 573 & $2 \cdot I$ & 0.1923 \\
\hline 607 & 595 & $2 \cdot 2$ & $0.092 \mathrm{I}$ \\
\hline 608 & $66 \mathrm{I}$ & $0.15 ?$ & 0.0271 ? \\
\hline
\end{tabular}


From the points for $Q_{x}$ in Fig. 6, a first approximate curve for relative spectral emission was drawn. Let the values on this curve be $E_{\lambda A}$. Then the ratios

$$
\rho_{1}=\frac{\int E_{\lambda A} S_{\lambda} T_{\lambda x}}{\int E_{\lambda A} S_{\lambda} T_{\lambda 604}}
$$

were calculated, and used to predict the experimental results.

The responses $R_{x}$ actually obtained with each filter give the true ratios

$$
\rho_{2}=\frac{R_{x}}{R_{604}} .
$$

When $\rho_{1}$ and $\rho_{2}$ differ, the latter is used to correct the experimental results, viz.

$$
\frac{\rho_{2}}{\rho_{1}}=\rho_{3} .
$$

$Q_{x} \rho_{3}=$ corrected relative spectral energy for each filter, when $Q_{604}=$ Io०.

\begin{tabular}{|c|c|c|c|c|c|c|}
\hline Filter & $E_{\lambda} S_{\lambda} T_{\lambda}\left(\zeta_{x}\right)$ & $\zeta_{x} / \zeta_{604}=\rho_{1}$ & $R_{x} / R_{604}=\rho_{2}$ & $\rho_{2} / \rho_{1}=\rho_{3}$ & $\begin{array}{c}Q_{x} \rho_{3} \\
\lambda_{530}\end{array}$ & Mean $\lambda$ \\
\hline OV I & $201 \cdot 0$ & $I \cdot I 6$ & 0.885 & 0.763 & $2 \cdot 79$ & 395 \\
\hline $601+O N 33$ & $227 \cdot 7$ & $\mathrm{I} \cdot 32$ & I. 33 & I.007 & 27.83 & \\
\hline $602+\mathrm{ON}_{32}$ & $66 \cdot 66$ & 0.385 & 0.372 & 0.966 & 45.63 & 466 \\
\hline $603+\mathrm{ON}_{31}$ & $79 \cdot 34$ & 0.459 & 0.460 & I. 002 & $77 \cdot 08$ & $49 \mathrm{I}$ \\
\hline 604 & $173.0^{\circ}$ & & - & - & $97 \cdot 56$ & 516 \\
\hline 605 & 108.75 & 0.629 & 0.708 & $I \cdot 126$ & $95.5 \mathrm{I}$ & 542 \\
\hline 606 & $26 \cdot 67$ & 0.154 & 0.186 & $\mathrm{I} \cdot 208$ & $59 \cdot 45$ & 572 \\
\hline 607 & $31 \cdot 00$ & 0.179 & 0.195 & I.089 & 25.65 & 592 \\
\hline 608 & $2 \cdot 27$ & 0.013 & 0.013 ? & I? & $6.93 ?$ & 622 \\
\hline
\end{tabular}

TABLE 4. SPECTRAL COMPOSITION OF ARTIFICIAL LIGHT SOURCE (correction of first approximate results)

In Table 4 are given the details of these calculations for filtered blue light from the substandard lamp. The second column lists areas of the curves $E_{\lambda A} S_{\lambda} T_{\lambda x}$ plotted against $\lambda\left(\zeta_{x}\right)$. Columns 3-5 give values of $\rho_{1}, \rho_{2}$ and $\rho_{3}$, for the various filters. The sixth column $Q_{x} \rho_{3}$ gives relative spectral energy for each filter, based on $\lambda_{530} \equiv 100$, the estimated region of maximal emission. The last column shows recalculated values for mean $\lambda$, based on curves $E_{\lambda A} S_{\lambda} T_{\lambda x}$.

The final corrected values for relative spectral energy for each filter are plotted on Fig. 7, together with the calculated relative energy curve (based on $\mathcal{F}_{\lambda} T_{\lambda}$ ). The degree of agreement, which can be seen from inspection, seems reasonable enough to trust the method for measurement of animal luminescence. 


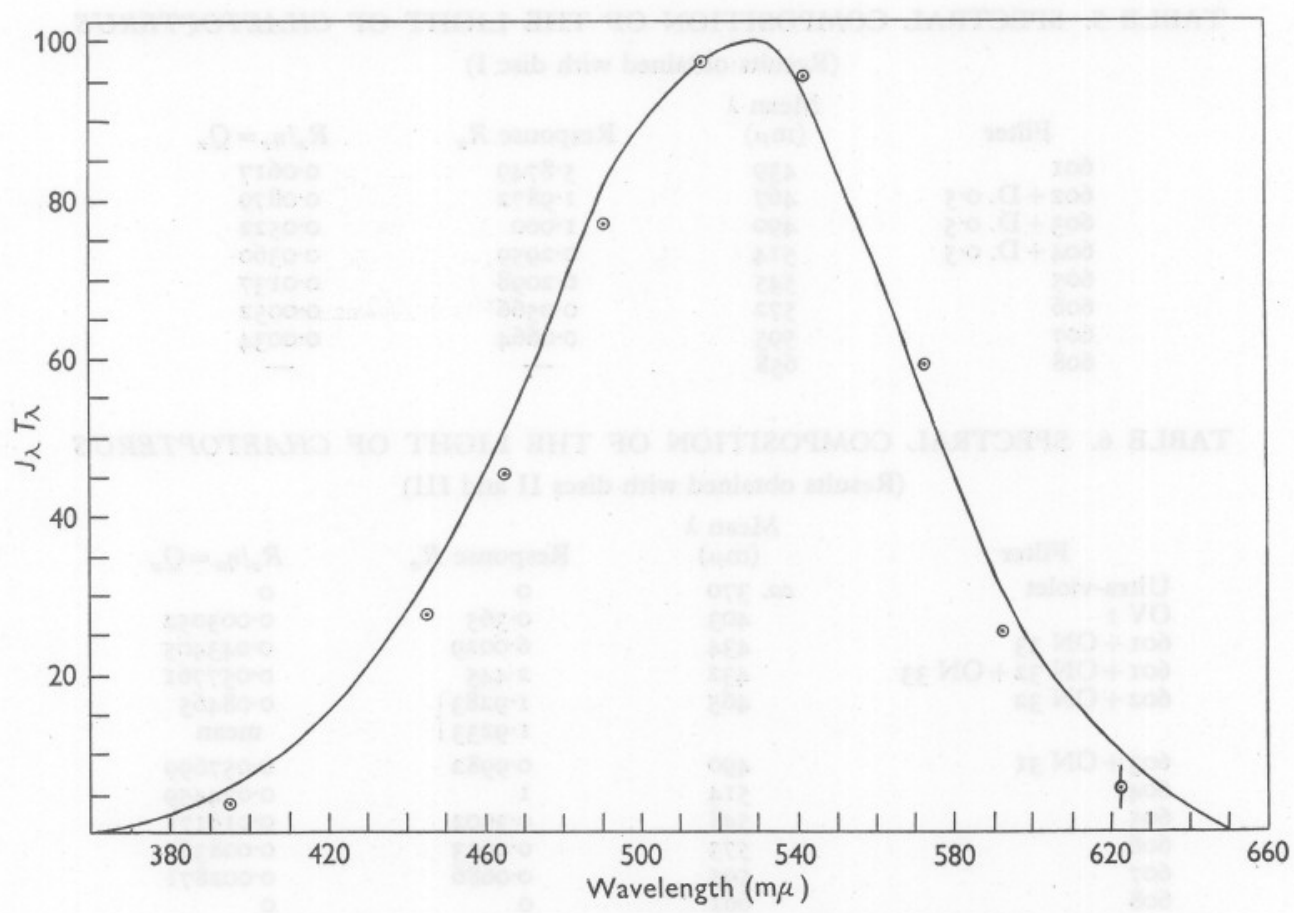

Fig. 7. Curve for relative spectral energy of artificial light (lamp $2360^{\circ} \mathrm{K}+$ Chance $\mathrm{OB} 2$ ). The points are corrected measurements made with the various filters, and plotted against mean $\lambda$ (determined from curves $E_{\lambda A} S_{\lambda} T_{\lambda x}$ ).

\section{MEASUREMENTS OF THE LIGHT OF CHAETOPTERUS}

As a first attempt, the light of Chaetopterus was measured by means of disc I, containing Ilford filters $60 \mathrm{I}$ to 608 . This disc was designed for green light. It was rotated at various speeds, varying from I to $3 \mathrm{rev}$./sec. The data obtained are summarized in Table 5, and first approximate estimations of relative spectral energy are plotted against $\lambda$ in Fig. 8 (mean $\lambda$ for each filter based on curves $S_{\lambda} T_{\lambda}$ ).

From these preliminary results it appeared that the light possessed a maximum well into the blue, around $460 \mathrm{~m} \mu$, and discs II and III were devised, accordingly, to extend the spectral range of analysis. Discs II and III were spun at low speeds, around $0.5 \mathrm{rev} . / \mathrm{min}$, at which rate it was possible to use a condenser $(0.05 \mu \mathrm{F})$ to filter off most of the noise. The data obtained with discs II and III are shown in Table 6 , and values for relative spectral energy are plotted in Fig. 9 against mean $\lambda$ (derived from curves $S_{\lambda} T_{\lambda}$ ).

In order to correct these values, the same procedure was employed, as described in the previous section. First approximate values for relative 
TABLE 5. SPECTRAL COMPOSITION OF THE LIGHT OF CHAETOPTERUS (Results obtained with disc I)

$\begin{array}{lccc}\text { Filter } & \begin{array}{c}\text { Mean } \lambda \\ (\mathrm{m} \mu)\end{array} & \text { Response } R_{x} & R_{x} / \eta_{x}=Q_{x} \\ 601 & 439 & 5.8749 & 0.0617 \\ 602+\mathrm{D} .0 .5 & 467 & 1.9872 & 0.0879 \\ 603+\mathrm{D} .0 .5 & 490 & 1.000 & 0.0522 \\ 604+\mathrm{D} .0 .5 & 514 & 0.2959 & 0.0360 \\ 605 & 545 & 0.2098 & 0.0137 \\ 606 & 572 & 0.0566 & 0.0052 \\ 607 & 595 & 0.0664 & 0.0034 \\ 608 & 658 & - & -\end{array}$

TABLE 6. SPECTRAL COMPOSITION OF THE LIGHT OF CHAETOPTERUS (Results obtained with discs II and III)

Filter

Ultra-violet

OV I

$60 \mathrm{I}+\mathrm{ON} 33$

$60 \mathrm{I}+\mathrm{ON} 32+\mathrm{ON}_{33}$

$602+\mathrm{ON}_{32}$

$603+\mathrm{ON}_{31}$

604

605

606

607

608
Mean $\lambda$

$(\mathrm{m} \mu)$

ca. 370

403

434

432

465

490
514

548

573

595

$66 \mathrm{I}$
Response $R_{x}$

0

0.365

6.0029

$2 \cdot 445$

I. 9283

I.9233

0.9982

I

0.3902

0.0913

0.0686

o
$R_{x} / \eta_{x}=Q_{x}$

○

0.003052

0.043405

$0.05776 \mathrm{r}$

0.08465

mean

0.057699

0.034459

0.016171

$0.00836 \mathrm{I}$

$0.00287 \mathrm{I}$

$\circ$

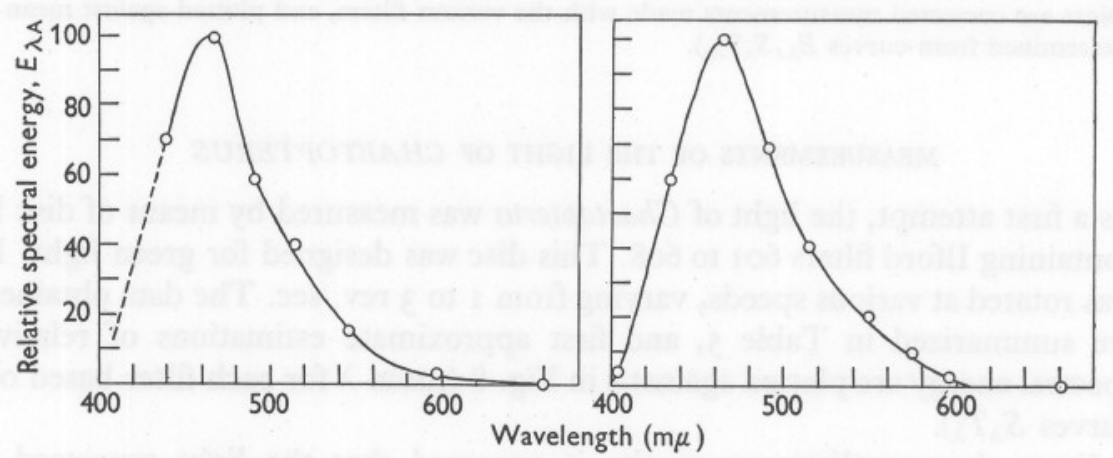

Fig. 8

Fig. 9

Fig. 8. Spectral composition of the light of Chaetopterus. Approximate curve based on records obtained with disc I. Mean $\lambda$ for each filter obtained from curves $S_{\lambda} T_{\lambda}$.

Fig. 9. Spectral composition of the light of Chaetopterus. Approximate curve based on records obtained with discs II and III. Mean $\lambda$ for each filter obtained from curves $S_{\lambda} T_{\lambda}$. 
spectral emission $E_{\lambda_{A}}$ were estimated from a curve resembling that in Fig. 9, and these values were used to draw curves for $E_{\lambda A} S_{\lambda} T_{\lambda x}$ (Fig. Io). Computed values are listed in Table 7 , together with subsequent calculations to determine corrected values for spectral emission. Final values are collected in Fig. II, which depicts a corrected spectral emission curve. Maximal emission occurs at about $465 \mathrm{~m} \mu$, well into the blue. There is no emission in the ultra-violet, and emission in the red, above $600 \mathrm{~m} \mu$, is negligible.

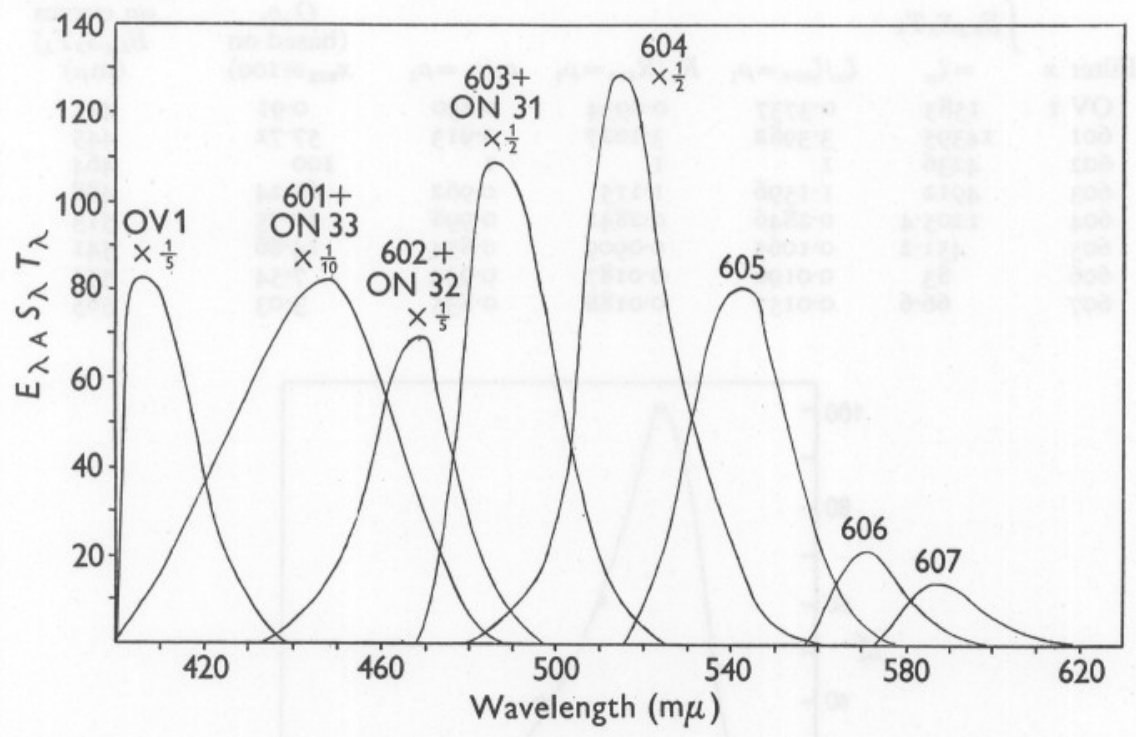

Fig. 10. Curves for $E_{\lambda A} S_{\lambda} T_{\lambda}$ against $\lambda$, based on first approximate measurements of relative spectral emission of Chaetopterus light.

\section{COMMENT}

Most of the light of Chaetopterus is concentrated in the blue region of the spectrum, more so than that of any animal hitherto measured. Cypridina has a somewhat similar emission spectrum, with a maximum at ca. $480 \mathrm{~m} \mu$ (Coblentz \& Hughes, I926). Polynoid light is greenish, with maximal emission at about 5 I $5 \mathrm{~m} \mu$ (Nicol, I957).

The biological significance of the light of Chaetopterus still awaits an explanation. Chaetopterus is light-sensitive, and presumably could detect its own light. However, the spectral sensitivity of Chaetopterus in unknown, so it is not possible to relate this to the colour of the luminescence. Chaetopterus is preyed upon by various animals, including Limulus and coastal fish, which may have occasion to perceive the light.

Absorption curves are available for the eye pigments (rhodopsins) of marine coastal fish, and the curves can be used to represent the spectral sensitivity of 
these animals (Fig. I2) (Wald, I946; Kampa, I953). The spectral sensitivity curve of Limulus has been determined (Graham \& Hartline, 1935). This has a maximum at $520 \mathrm{~m} \mu$ (Fig. I2). In Fig. I3 I have drawn curves for 'luminous flux' of Chaetopterus light, based on visibility values taken from the curves of

TABLE 7. SPECTRAL COMPOSITION OF THE LIGHT OF CHAETOPTERUS

(Correction of first approximate results)

\begin{tabular}{|c|c|c|c|c|c|c|}
\hline Filter $x$ & $\begin{array}{c}E_{\lambda A} S_{\lambda} T_{\lambda} \\
=\zeta_{x}\end{array}$ & $\zeta_{x} / \zeta_{602}=\rho_{1}$ & $R_{x} / R_{602}=\rho_{2}$ & $\rho_{2} / \rho_{1}=\rho_{3}$ & $\begin{array}{c}Q_{x} \rho_{3} \\
\text { (based on } \\
x_{602} \equiv \mathrm{IOO)}\end{array}$ & $\begin{array}{c}\text { Mean } \lambda \text { (based } \\
\text { on curves } \\
\left.E_{\lambda A} S_{\lambda} T_{\lambda}\right) \\
(\mathrm{m} \mu)\end{array}$ \\
\hline OV r & I583 & 0.3737 & 0.0934 & 0.250 & 0.91 & 4II \\
\hline 601 & 14395 & $3 \cdot 3982$ & $3 \cdot 1027$ & 0.913 & $57 \cdot 72$ & 443 \\
\hline 602 & 4236 & I & I & I & IOO & 464 \\
\hline 603 & 4912 & I·I 596 & I'I I5 & 0.962 & $6 I \cdot 24$ & 488 \\
\hline 604 & $1205^{\circ} 4$ & 0.2846 & $0.284 \mathrm{I}$ & 0.998 & $40 \cdot 75$ & $5 I_{3}$ \\
\hline 605 & $45 \mathrm{I} \cdot 2$ & 0.1065 & 0.0909 & 0.854 & 14.86 & 541 \\
\hline 606 & 83 & 0.0196 & 0.0187 & 0.954 & $7 \cdot 54$ & 571 \\
\hline 607 & $66 \cdot 6$ & 0.0157 & 0.0188 & 0.835 & 3.03 & 585 \\
\hline
\end{tabular}

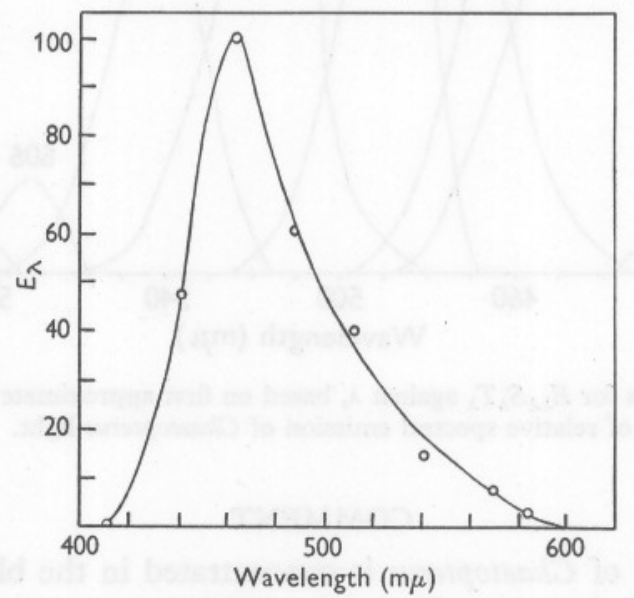

Fig. II. Corrected values for relative spectral energy of Chaetopterus light, and a spectral emission curve based on these values.

Fig. I2, and on human scotopic vision (C.I.E. values). The luminous efficiency of radiation is given by the ratio of total luminous flux to total radiant flux (Harvey, 1940). For human scotopic vision, Chaetopterus light is $67 \%$ efficient; for fish having visual purples with maxima at $505 \mathrm{~m} \mu$, Chaetopterus light is $71 \%$ efficient; and for the eye of Limulus, Chaetopterus light is $56 \%$ efficient. 


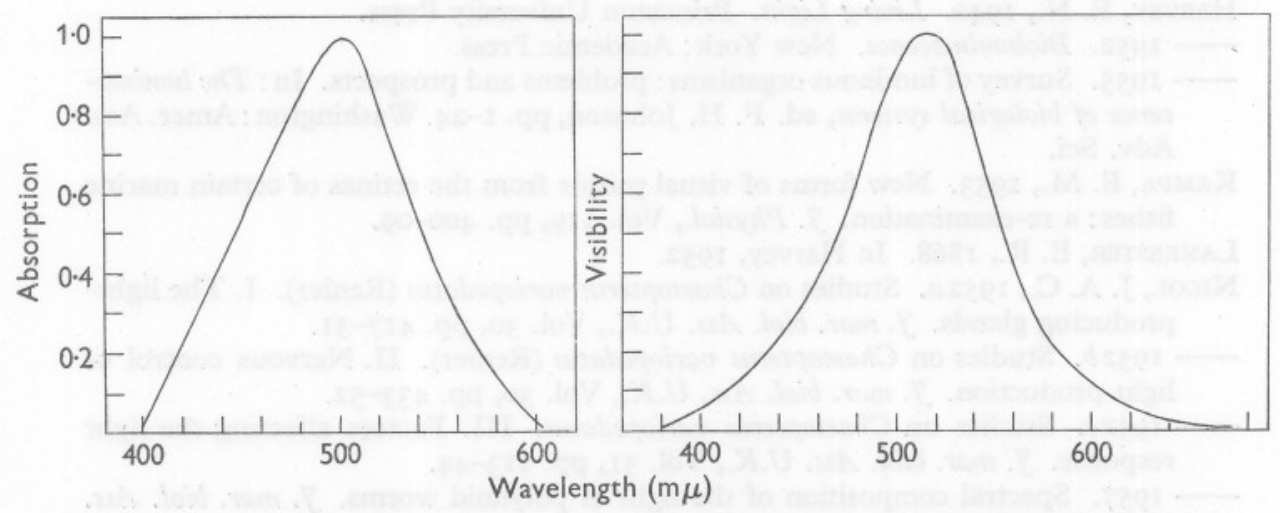

Fig. 12. Left, generalized absorption curve for visual purple of coastal marine fish (based on measurements of Wald, 1946, and Kampa, I953). Right, visibility curve for Limulus (based on measurements of Graham \& Hartline, 1935).

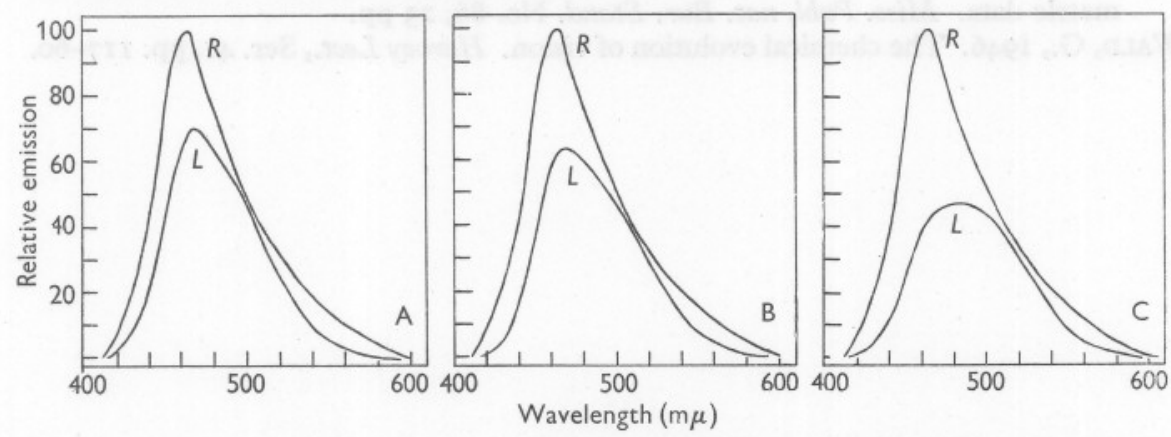

Fig. 13. Relative spectral energy curves (radiant flux) of Chaetopterus light, and estimated curves of luminous flux based on fish rhodopsin (A), human scotopic vision (B), and Limulus vision (c). $R$, radiant flux; $L$, luminous flux.

\section{SUMMARY}

The spectral composition of the light of Chaetopterus variopedatus has been measured by means of spectral filters and multiplier phototube. Spectral emission extends from about 405 to $605 \mathrm{~m} \mu$, with a maximum at about $465 \mathrm{~m} \mu$. The spectral curve of Chaetopterus light is compared with a human visibility curve (scotopic vision), a visibility curve for Limulus, and an absorption curve for fish visual purple. Luminous efficiencies, based on these curves, are calculated.

\section{REFERENCES}

Coblentz, W. W. \& Hughes, C. W., I926. Spectral energy distribution of the light emitted by plants and animals. Sci. Pap. U.S. Bur. Stand., Vol. 2I, pp. 52I-34 (no. 538 ).

Graham, C. H. \& HartLine, H. K., I935. The response of single visual cells to lights of different wave lengths. F. gen. Physiol., Vol. I8, pp. 917-31. 
Harvey, E. N., 1940. Living Light. Princeton University Press.

— 1952. Bioluminescence. New York: Academic Press.

- 1955. Survey of luminous organisms: problems and prospects. In: The luminescence of biological systems, ed. F. H. Johnson, pp. I-24. Washington: Amer. Ass. Adv. Sci.

KAMPA, E. M., I953. New forms of visual purple from the retinas of certain marine fishes: a re-examination. F. Physiol., Vol. I19, pp. 400-09.

LANKESTER, E. R., I868. In Harvey, 1952.

Nicol, J. A. C., I952 a. Studies on Chaetopterus variopedatus (Renier). I. The lightproducing glands. F. mar. biol. Ass. U.K., Vol. 30, pp. 4I7-3I.

- I952 $b$. Studies on Chaetopterus variopedatus (Renier). II. Nervous control of light production. F. mar. biol. Ass. U.K., Vol. 30, pp. 433-52.

- I952c. Studies on Chaetopterus variopedatus. III. Factors affecting the light response. F. mar. biol. Ass. U.K., Vol. 31, pp. I13-44.

- 1957. Spectral composition of the light of polynoid worms. F. mar. biol. Ass. U.K., Vol. 36, pp. 529-38.

SKoGLAND, J. F., I929. Tables of spectral energy distribution and luminosity for use in computing light transmissions and relative brightnesses from spectrophotometric data. Misc. Publ. nat. Bur. Stand. No. 86, 23 pp.

WALD, G., I946. The chemical evolution of vision. Harvey Lect., Ser. 4I, pp. II7-60. 